\title{
I Just Trust Him: The Notion of Consideration as a Barrier to Condom Use amongst Women Who Inject Drugs in Central Java
}

\author{
Antonia Morita Iswari Saktiawati ${ }^{1}$, Heather Worth $^{2}$, Elan Lazuardi ${ }^{1}$, Catherine Spooner ${ }^{2}$, \\ Yanri Wijayanti Subronto ${ }^{1}$, Retna Siwi Padmawati ${ }^{1}$ \\ ${ }^{1}$ Centre for Tropical Medicine-Research Collaboration Unit, Faculty of Medicine, Universitas Gadjah Mada, Yogyakarta, Indonesia; \\ ${ }^{2}$ International HIV Research Group, School of Public Health and Community Medicine, University of New South Wales, Sydney, \\ Australia. \\ Email: h.worth@unsw.edu.au
}

Received August $13^{\text {th }}, 2013$; revised September 12 ${ }^{\text {th }}, 2013$; accepted September $19^{\text {th }}, 2013$

Copyright (C) 2013 Antonia Morita Iswari Saktiawati et al. This is an open access article distributed under the Creative Commons Attribution License, which permits unrestricted use, distribution, and reproduction in any medium, provided the original work is properly cited.

\begin{abstract}
The HIV epidemic in Indonesia has risen sharply since 2004, from 2682 cases in 2004 to 19,973 in 2009. The main transmission route of HIV in Indonesia is injecting drug use. There is little research on women who inject drugs in Indonesia. In-depth interviews were carried out with 19 women who injected drugs in three small cities in central Java. The interviews explored the living conditions of the women and the context of HIV risk. The transcripts were coded and the data were thematically analyzed. In this paper we report on condom use with regular partners. Condom use was very low with their regular partners, even though both they and their partners were injecting drug users. The reasons women gave were that they trusted their partners (although they realised this trust was shaky). The women used traditional Javanese cultural concepts of consideration to explain why they did not use condoms. This was heightened by other cultural norms of women's place in Javanese society. Although the women in the study were marginalized because of their drug use, they still hold to many Indonesian cultural precepts - of consideration and care for the other above oneself in their relationships with their regular partners which impede condom use. While notions of consideration and harmony were used to explain non-condom use, the same notions could also be used in couple-counseling to assist.
\end{abstract}

Keywords: Central Java; Condom Use; Drug Use; Cultural Concept

\section{Introduction}

International research with general populations and people who inject drugs has identified numerous barriers to using a condom and identified that the barriers to using condoms vary with the type of partner (regular, casual or commercial sexual partner). In the context of regular sexual relationships, people are less motivated to use a condom because they perceive themselves to be at low risk [1-3]. Among people injecting drugs who have regular partners, consistent condom use was associated with greater self-efficacy, and negatively associated with regular partner's desire for pregnancy and needle sharing. Among those injectors with casual partners, having fewer sex partners was associated with consistent condom use. Positive attitudes toward condom use and partner norms supporting condom use were predictive of consistent use for both regular and casual partners [4]. In the context of women who inject drugs, the barriers of consistent condom use are trusting that their regular partner does not have HIV because they know them $[5,6]$, low risk perceptions, and discomfort in discussing condom use with partners [5,7], insufficient knowledge about how to access and use condoms [5], and the belief that condoms interfere in sexual pleasure [8].

International research with injecting drug users has identified that, life is quite different for women relative to men and these gendered experiences shape their HIV risk behaviours. For example, women who inject drugs have difficulties in negotiating condom use, particularly when they are dependent on men for drugs. While people who inject drugs often experience considerable social 
stigma, economic pressure, and lack of social support [7-9], women who inject drugs, in particular, often experience feelings of powerlessness, low self-esteem, and poor self-confidence as they are marginalized by society and this can influence their sexual relationship with their partners [10]. Therefore, it is important to take a gender perspective when discussing HIV risk amongst people who inject drugs.

Various contexts at familial level, societal level, and sexual-partnership level will influence sexual risk behaviours at the individual level [11]. For women who inject drugs these include less negotiation strength in terms of condom use due to male domination of sexual roles $[10,12,13]$, the stigma of injection drug use from the society which is even worse for women as they are expected to be good wives, mothers, daughters, or nurturers of families; and also gendered discrimination [14], which in turn, prompts their unsafe sexual practices.

While there is a significant body of international research relating to condom use among people who inject drugs, and among women who inject drugs in particular [4,11,15-21], there is little research about women who inject drugs in Indonesia. One reason for this lack of research with women who inject drugs in Indonesia is that only $1 \%-8 \%$ of injectors in research studies are women [22]. The HIV epidemic in Indonesia has risen sharply since 2004, making it among "the fastest growing in Asia" [23]. The number of reported cases of HIV in Indonesia increased from 2682 cases in 2004 to 19,973 in 2009 [24]. The main transmission route of HIV in Indonesia has been through blood when sharing injecting equipment to use drugs. Consequently, people who inject drugs have been a focus of concern for Indonesia's HIV strategy. Among those who inject drugs, sharing injecting equipment is not the only risk for HIV infection. HIV can also be transmitted via unprotected sexual contact with an HIV-infected person, whether that person is a regular sexual partner, a casual sexual partner, or a commercial sexual partner. It is well established that condom use can prevent HIV transmission from an infected person to an uninfected person [25].

Results of biological-behavioural surveillance among people who inject drugs in multiple sites within Indonesia identify that unprotected sex is prevalent, irrespective of the type of partner [22]. Pisani [26] indicated that condom use among people who inject drugs with all types of partners in three cities of Indonesia was not consistentalmost $90 \%$ of people injecting drugs who bought sex from a sex worker in the last year seldom or never used a condom.

In this paper we report on data from a qualitative study of HIV risk among women who inject drugs in Java, Indonesia. While the study focused primarily on injecting behaviour [27], we also asked about condom use.

\section{Method}

\subsection{Study Population and Sample}

The study population was women who inject drugs in three small cities in central Java: Yogyakarta, Salatiga and Solo. In developing the research study, consultations were conducted from August 2009 to January 2010 with people working in non-government organisations (NGOs), government health services (including methadone programs and needle and syringe programs (NSP)), community organisations, prisons and police. Consultations identified that injecting drug use by women in the region was a particularly hidden behaviour due to fear of police and social stigma. We were warned that there were few women who injected drugs in the area and that nobody would want to talk with researchers. Consequently, it was clear that recruitment would only be possible via people who had pre-existing relationships with women who inject drugs. Participants were recruited via outreach workers working in three non-governmental organizations in two cities and the local branch of the National AIDS Commission in one city. The research method was chosen because the respondents were very closed and hidden, and focus group discussions or questionnaires would not elicit the kind of in-depth information we sought.

Inclusion criteria for participation in the study were being female, aged 18 years or older, injecting drug use within the previous month, and living or staying in a study site (Yogyakarta, Salatiga or Solo) during the data collection period. The final study sample comprised 19 women, two from Yogyakarta, 10 from Solo, and 7 from Salatiga. One participant withdrew from the study because in the middle of the interview, she experienced symptoms of drug withdrawal, and refused to meet again for interview.

The two interviewers were Indonesian women employed as social research trainees as part of an AusAIDfunded capacity building project. They were trained in interview method by a senior social researcher from the University of New South Wales. The study was approved by the ethics committees of the UNSW and Universitas Gadjah Mada.

\subsection{Data Collection and Analysis}

Interviews were conducted in locations that were private, quiet, comfortable and safe. These included public places (cafes), and private spaces (e.g. the home of an outreach worker). Interviews were conducted in Indonesian language. The interview lasted for 2 hours, on average. Interviews were conducted until there was no novel data found (data were "saturated"). Two researchers and one supervisor coded the data, and no software packages were 
used for management or analysis of the data. For each interview, the participant was asked for written informed consent to participate after receiving information about the purpose of the study and permission to record the interview. All participants were asked to provide and use a pseudonym so that there was no risk of information being attributed to individuals. Written notes and audio recordings only included these identifiers. Participants were reimbursed for expenses incurred in their participation (e.g. phone credit, travel) and for their time assisting with recruitment and/or participating in an interview. The interview schedule was designed to explore the lives of the women and the context of HIV risk. The interview investigated background (e.g. family background, initiation of drug use, sexual behaviour - reasons for not using condoms, HIV testing, stigma and discrimination). Audio recordings were made of each interview. Qualitative data analysis was consistent with grounded theory with the analysis drawing meaning from the data rather than testing theories. All interview data was transcribed and translated into English. The transcripts were coded, and coded data were copied into separate documents; one for each topic.

\section{Results and Discussion}

All of the study participants had injected an impure form of heroin called putaw or etep in the previous month. Injection of other drugs was rare. The average age was 25 , ranging from 19 to 36 years. Three-quarters of the sample were educated up to senior high school level and one woman had tertiary education. The women had lived in the city of interview for an average of 16 years. Seventeen women were Javanese, while the remaining two were of mixed Indonesian ethnicity; that is, one parent from Java and the other from elsewhere in Indonesia.

Half of the women lived in a boarding house; three did so with their boyfriend and one with her husband. The others lived in their parents' home, with parents-in-law, or with their husband in a home.

Consistent with international literature [28], the women in our study protected themselves by being reclusive and limiting social interactions to a small group of friends with the same activity of illegal drug injection. In this group, the women tended to depend upon their boyfriend or friends to obtain drugs, injecting equipment, or condoms.

During the year prior to the interviews, 15 of the 19 women had been sexually active and this was mostly in the context of an ongoing relationship, mostly with a man who also injected drugs. All of the 15 women had a regular sexual partner in the past year: ten had lived with their spouse or boyfriend, and seven had a boyfriend with whom they did not live. Two had both over this time.
Only one woman reported that she had a casual sexual partner in the past year, but three women reported a commercial sexual partner in the previous year. These three women were being "pimped" by their boyfriend to obtain cash to buy their drugs. Only one of these women regularly used condoms with their commercial partners. Desi used condoms with clients because they demanded them, "They want to keep safe... They are afraid to get a disease, they think like that, so I prepare myself with condoms". Note here that Desi was not asserting the need to use condoms for her own health; rather it was because the client clients demanded them. In fact, she did not use condoms with her regular boyfriend, "After I inject myself, I get horny, I want to have sex. But I never use a condom when I have sex with my boyfriend, while I always use condoms with other guys".

The other two women who reported commercial sex rarely - if ever, used condoms with clients. When questioned about why she took sexual risks with clients, Maya said, "Maybe it is because I feel like I'm in a hurry - my mind says, 'forget it'. That happens when I have sex with the guys who pay me. Only the ones who pay me. I don't think I am that much in need of money, right. So, forget it". Rosa said, "Yeah, I do have another man (a client) I have sex with... I didn't use condoms because I didn't want to. The problem is I also never use condoms with my boyfriend. It just doesn't feel right, using condoms".

The women who were not selling sex were nonetheless acting outside of the expectations of Javanese women in terms of their injecting behaviour. Though they were clearly ashamed of their injecting drug use, these women were in a monogamous regular relationship, and they had established a social hierarchy in which sexual "promiscuity" was at the bottom:

But they're slut girls... they're considered low class, junkies are also considered low but they're lower... sluts are considered lower class because they're easy, they can be taken here and taken there... used here, used there. That's why junkies are more respectable, what I mean is when we use drugs, we only use drugs... we don't get that low-to let people use us. (Sulis).

The women trusted their partners. Desi said:

"It's trust. I really trust my boyfriend. I strongly believe that he never has sex with another girl".

In general worldwide, it is understandable that women in regular relationships tend not to use condoms [29-32]. It is difficult to expect women to use a condom within the context of a regular relationship in which it is expected that each partner is monogamous. As was the case with sharing needles, most of the women in this study, particularly those who lived with their partners, tended to say it was reasonable not to use a condom because they 
trusted their partner.

However, in the situation in which other potentially high risk behaviours are present (in this case a partner who injects), this trust is not so certain. In actuality the women hoped that their partners would be faithful, even though they realised that their partner could not be trusted [33]. Surveys of people who inject drugs in Indonesia (over $90 \%$ of the samples were men) have shown that they often have casual, multiple and/or paid sexual partners aside from their regular partner [22].

Well I am not really sure about it, but I rarely know that he has sex with another woman. I've never seen or heard before that he slept with other girls. Actually, he always stands by me, whenever I need him; he's always there for me. Well, we live in one boarding house [in one room], Miss (Desi).

Similarly, Rosa initially said that she trusted her boyfriend, but then she changed her mind and admitted to not really trusting him because she felt that it was impossible for a man to not cheat on his partner.

I But, are you also sure that he only has sex with you?

$R$ Yeah, I am sure. But I don't know actually, whether he has had an affair or not. Well for me, a man is a man, it's just so impossible for a man to never cheat on his partner, right? But with him, I can only trust. I just trust him (Rosa).

This feeling of trust seemed to be related to the small social network that the women had, in which trust and loyalty were essential for survival. Further, some of the women in the study seemed to place great trust in their partners because they did not have other people to rely on. Requesting that partners use condoms suggested that they did not trust their partner and they did not want to risk the relationship by doing so. Lau et al. [7] also found that women who inject drugs who had a male partner who injects drugs often do not practice HIV-related protective behaviours since it could be interpreted as "not breaching the trust", although there was no reason to believe that their male partner would not get infected from other sources.

The situation of "trust" for these women is heightened by Javanese cultural imperatives. Women in central Java are expected to behave in a manner that is polite and "proper" [34]. Sex is rarely discussed openly, relationships are expected to be dominated by men, and premarital sex is not permitted [35]. Although the women in the study are outside Javanese mainstream culture in many ways because of their drug use, they still hold to many cultural precepts - of consideration and care for the other above oneself in their relationships with their regular partners.

Javanese culture has a belief in keeping harmonywithin oneself and within the community. This can mean sacrificing individual wants for the sake of community harmony and above all avoiding confrontation. Through consideration, Javanese people try to keep the environment in a "rukun" or peaceful condition [36]. The women explained that consideration came from both sides; they considered partner's feeling and the same went with their partners. This consideration could be a benefit for condom use practices since their partners would understand if the women wanted to use condoms. However, the Javanese character of pekewuh (fear of disappointing others who are respected) and isin (a sense of "uneasiness" with respect to behaviour and expression which is counter to social values) amplifies concerns about breaching traditional gender roles. Thus, in reality, it was the women who considered their partner's feeling more than the men; thus safer sex did not happen.

Actually he also likes it better without condoms too... he said that it is not good... I don't know for sure... he loves to have sex without condoms... I just give what he wants... I mean just follow his desire. I don't want to fight over that kind of thing. (Idra).

This consideration was heightened by the central Javanese expectation of women pleasing men. In Javanese traditional culture everything that was good was intended for the father who was the "head of the family". A wife had a duty to serve her husband. Although these expectations have lessened in this modern era, it has influenced the relationship between men and women in Javanese society. In addition, this consideration is also a result of the dependency of the women to their partners to get drugs and needles. To be always able to get drugs and needles, the women were willing to please their partners, for instance not using condom if the partners did not like that. Women did not report being pressured to not use a condom. Rather, women talked about wanting to be considerate of their partner's feelings and, to a lesser extent, of partners being considerate of their feelings.

With my current boyfriend, once I asked him to use a condom, so he used a condom but he said that he felt uncomfortable, then I said, "okay, just peel it off, it's okay..." So he peeled it off. (Icha).

Since 2002 I found out my HIV status, I started using condoms. But, he [Nana's boyfriend who is also HIV positive] was so sick that time, so I did not have the heart to push him to wear condoms all the time (Nana).

Despite the gendered nature of Javanese culture, most of the women asserted that there was generally equality within their relationships. For example, Indah stated that "There are no differences between women and me; the feeling is the same... The position is the same".

But while few of the women mentioned the gendered power differentials between them and their male partners, they obviously understood that men and women experi- 
ence their sexual lives differently. Dwi said:

Men tend to be careless, and never think of the future... If [a girl] is infected by HIV, what could she say? Your life is already stagnant at this point, you never get a man, never get a husband, and never are able to get pregnant. Men are different; they can do anything they want. What about girls? They still think, but men do not think as the girls do. As long as they are happy, everything is fine. That is my opinion (Dwi).

Interestingly, the women did not consider that their non-use of condoms was putting themselves at risk. When asked about the consequences of sex without condoms, it was always answered in ways that imputed risk only to men, even in the case of the three women who were selling sex. For example, when asked about transmission of the virus Rosa answered, "But as far as I know, my boyfriend never does anything bad behind my back".

\section{Conclusions}

Condom use amongst women who inject drugs in Java is shaped by the context in which the women lived, and very little by the type of sexual partner. From the interviews with the women, the Javanese cultural context evidently influenced their sexual behaviour. This context includes gendered power relations in which women have few negotiating rights. Javanese culture produces a generally cohesive and considerate society, but it is one in which women tend to give more weight and consideration to their male partners. Male partners were central to these women's lives; they had few friends outside of their male-dominated injecting world.

Javanese women are also expected to be polite and trust their partners, and this tends to mitigate against negotiating condom use. This trust, which is found in studies in other countries, appeared here to stem from Javanese cultural traditions. For the majority of the women, trust and consideration of a partner's wishes were foremost in terms of whether or not she used condoms. This was even so for two of the three women who sold sex. This trust puts these women at considerable risk of HIV, not only through their injecting behaviour but also through sexual practice. It also puts their partners at risk of HIV - a consideration which does not seem to occur to them.

If consideration of the other is cultural bedrock for Javanese women, then there may be ways where it could be utilised for HIV prevention, by showing how condom use is an act of consideration. Most of the women were in a regular relationship, and couple based-interventions could be a way forward. Couples counseling could be effective in settings where women's decision-making power is limited and male involvement and support are critical to enable behaviour to change within couples [37].
In a couple-based intervention, they could talk about how to care for their partner by using condoms to keep themselves safe sexually from HIV.

\section{REFERENCES}

[1] P. van Empelen, H. P. Schaalma, G. Kok and M. W. Jansen, "Predicting Condom Use with Casual and Steady Sex Partners among Drug Users," Health Education Research, Vol. 16, No. 3, 2001, pp. 293-305. http://dx.doi.org/10.1093/her/16.3.293

[2] T. D. Conley and B. E. Collins, "Differences between Condom Users and Condom Nonusers in Their Multidimensional Condom Attitudes," Journal of Applied Social Psychology, Vol. 35, No. 3, 2005, pp. 603-620. http://dx.doi.org/10.1111/j.1559-1816.2005.tb02137.x

[3] A. Štulhofer, V. Baćak, D. Ajduković and C. Graham, "Understanding the Association between Condom Use at First and Most Recent Sexual Intercourse: An Assessment of Normative, Calculative, and Habitual Explanations," Social Science \& Medicine, Vol. 70, No. 12, 2010, pp. 2080-2084.

http://dx.doi.org/10.1016/j.socscimed.2010.02.030

[4] F. Kapadia, M. Latka, Y. Wu, S. Strathdee, M. Mackesy-Amiti and S. Hudson, "Longitudinal Determinants of Consistent Condom Use by Partner Type among Young Injection Drug Users: The Role of Personal and Partner Characteristics," AIDS and Behaviour, Vol. 15, No. 7, 2011, pp. 1309-1318.

http://dx.doi.org/10.1007/s10461-009-9569-3

[5] A. M. Nyamathi, C. Lewis, B. Leake, J. Flaskerud and C. Bennett, "Barriers to Condom Use and Needle Cleaning among Impoverished Minority Female Injection Drug Users and Partners of Injection Drug Users," Public Health Reports, Vol. 110, No. 2, 1995, pp. 166-172.

[6] K. Shannon, T. Kerr, S. Allinott, J. Chettiar, J. Shoveller and M. W. Tyndall, "Social and Structural Violence and Power Relations in Mitigating HIV Risk of Drug-Using Women in Survival Sex Work," Social Science \& Medicine, Vol. 66, No. 4, 2008, pp. 911-921.

http://dx.doi.org/10.1016/j.socscimed.2007.11.008

[7] J. Lau, "Comparing Prevalence of Condom Use during Commercial Sex and Its Related Factors among Female Sex Workers Injecting (FSW-IDU) or Not Injecting Drugs (FSW-N-IDU) in China," Culture, Health and Sexuality, Vol. 11, No. 1, 2009, pp. 53, 54.

[8] A. K. S. Krishnan, E. Hendriksen, S. Vallabhaneni. S. L. Johnson, S. Raminani, N. Kumarasamy, et al., "Sexual Behaviors of Individuals with HIV Living in South India: A Qualitative Study," AIDS Education and Prevention Vol. 19, No. 4, 2007, pp. 334-345.

http://dx.doi.org/10.1521/aeap.2007.19.4.334

[9] S. Y. P. Choi, Y. W. Cheung and K. Chen, "Gender and HIV Risk Behavior among Intravenous Drug Users in Sichuan Province, China," Social Science \& Medicine, Vol. 62, No. 7, 2006, pp. 1672-1684.

http://dx.doi.org/10.1016/j.socscimed.2005.08.046

[10] UNODC, "HIV/AIDS Prevention and Care for Female 
Injecting Drug Users," UNDOC, 2006.

[11] V. Chakrapani, P. A. Newman, M. Shunmugam and R. Dubrow, "Prevalence and Contexts of Inconsistent Condom Use among Heterosexual Men and Women Living with HIV in India: Implications for Prevention," AIDS Patient Care and STI, Vol. 24, No. 1, 2010, pp. 48-58.

[12] J. Gu, R. Wang, H. Chen, J. T. F. Lau, L. Zhang, X. Hu, et al., "Prevalence of Needle Sharing, Commercial Sex Behaviors and Associated Factors in Chinese Male and Female Injecting Drug User Populations," AIDS Care, Vol. 21, No. 1, 2009, pp. 31-41. http://dx.doi.org/10.1080/09540120802068787

[13] J. Gu, H. Chen, X. Chen, J. T. F. Lau, R. Wang, C. Liu, et al., "Severity of Drug Dependence, Economic Pressure and HIV-Related Risk Behaviors among Non-Institutionalized Female Injecting Drug Users Who Are Also Sex Workers in China," Drug and Alcohol Dependence, Vol. 97, No. 3, 2008, pp. 257-267. http://dx.doi.org/10.1016/j.drugalcdep.2008.03.029

[14] S. Pinkham and K. Malinowska-Sempruch, "Women, Harm Reduction, and HIV," 2007.

http://www.soros.org/initiatives/health/focus/ihrd/articles _publications/publications/women_20070920/women_20 070920.pdf

[15] P. M. Spittal, K. J. P. Craib, E. Wood, N. Laliberté, K. Li, M. W. Tyndall, et al., "Risk Factors for Elevated HIV Incidence Rates among Female Injection Drug Users in Vancouver," Canadian Medical Association Journal, Vol. 166, No. 7, 2002, pp. 894-899.

[16] C. Sterk, K. Theall, K. Elifson and D. Kidder, "HIV Risk Reduction among African-American Women Who Inject Drugs: A Randomized Controlled Trial," AIDS and Behaviour, Vol. 7, No. 1, 2003, pp. 73-86. http://dx.doi.org/10.1023/A:1022565524508

[17] H. Klee, "HIV Risks for Women Drug Injectors: Heroin and Amphetamine Users Compared," Addiction, Vol. 88, No. 8, 1993, pp. 1055-1062. http://dx.doi.org/10.1111/j.1360-0443.1993.tb02124.x

[18] M. Magnus, I. Kuo, G. Phillips $2^{\text {nd }}$, A. Rawls, J. Peterson, L. Montanez, et al., "Differing HIV Risks and Prevention needs among Men and Women Injection Drug Users (IDU) in the District of Columbia," Journal of Urban Health, Vol. 90, No. 1, 2012, pp. 157-166. http://dx.doi.org/10.1007/s11524-012-9687-5

[19] W. M. Wechsberg, W. K. Luseno, W. K. Lam, C. D. Parry and N. K. Morojele, "Substance Use, Sexual Risk, and Violence: HIV Prevention Intervention with Sex Workers in Pretoria," AIDS and Behaviour, Vol. 10, No. 2, 2006, pp. 131-137. http://dx.doi.org/10.1007/s10461-005-9036-8

[20] L. Shulga and T. Andreeva, "Condom Use among Longterm Intimate Partners Using Drugs Baseline Results from a Randomized Trial in Ukraine," Retrovirology, Vol. 9, Suppl. 1, 2012, p. P109. http://dx.doi.org/10.1186/1742-4690-9-S1-P109

[21] A. Uuskula, K. Abel-Ollo, A. Markina, L. A. McNutt and R. Heimer, "Condom Use and Partnership Intimacy among Drug Injectors and Their Sexual Partners in Estonia,"
Sexual Transmitted Infections, Vol. 88, No. 1, 2012, pp. 58-62. http://dx.doi.org/10.1136/sextrans-2011-050195

[22] Indonesian National AIDS Commission, "Integrated Biological-Behavioral Surveillance among Most-at-Risk Groups (AMRG) in Indonesia-Surveillance Highlights Injecting Drug Users," National AIDS Commission, Indonesia, 2007.

[23] UNAIDS, "Report on the Global AIDS Epidemic," 2008. http://www.unaids.org/en/KnowledgeCentre/HIVData/Gl obalReport/2008/2008_Global_report.asp

[24] Indonesian National AIDS Commission, "Republic of Indonesia Country Report on the Follow up to the Declaration of Commitment on HIV/AIDS (UNGASS) Reporting Period 2008-2009," National AIDS Commission Republic of Indonesia, 2009.

[25] S. Weller and K. Davis, "Condom Effectiveness in Reducing Heterosexual HIV Transmission (Cochrane Review)," The Cochrane Library, No. 4, 2003.

[26] E. Pisani, Dadun, P. K. Sucahya, O. Kamil and S. Jazan "Sexual Behavior among Injection Drug Users in 3 Indonesian Cities Carries a High Potential for HIV Spread to Noninjectors," Journal of Acquired Immune Deficiency Syndromes, Vol. 34, No. 4, 2003, pp. 403-406. http://dx.doi.org/10.1097/00126334-200312010-00007

[27] C. Spooner, A. M. I. Saktiawati, E. Lazuardi, H. Worth, Y. W. Subronto and R. S. Padmawati, "Women Who Inject Drugs and HIV Risk in Central Java, Indonesia,” International HIV Research Group, Sydney, 2010.

[28] A. Persson and W. Richards, "Vulnerability, Gender and 'Proxy Negativity': Women in Relationships with HIVPositive Men in Australia," Social Science \& Medicine, Vol. 67, No. 5, 2008, pp. 799-807. http://dx.doi.org/10.1016/j.socscimed.2008.05.010

[29] A. E. Miranda, N. C. Figueiredo, W. McFarland, R. Schmidt and K. Page, "Predicting Condom Use in Young Women: Demographics, Behaviours and Knowledge from a Population-Based Sample in Brazil," International Journal of STD \& AIDS, Vol. 22, No. 10, 2011, pp. 590-595. http://dx.doi.org/10.1258/ijsa.2009.009104

[30] L. Norman, C. Garriga and L. Cintron, "Condom Use Patterns among Women Who Live in Public Housing Developments in Ponce, Puerto Rico," Journal of Health Care for the Poor and Underserved, Vol. S22, No. 4, 2011, pp. 122-145. http://dx.doi.org/10.1353/hpu.2011.0160

[31] L. DePadilla, M. Windle, G. Wingood, H. Cooper and R. DiClemente, "Condom Use among Young Women: Modeling the Theory of Gender and Power," Health Psychology, Vol. 30, No. 3, 2011, pp. 310-319. http://dx.doi.org/10.1037/a0022871

[32] L. Callegari, C. C. Harper, A. van der Straten, M. Kamba, T. Chipato and N. S. Padian, "Consistent Condom Use in Married Zimbabwean Women after a Condom Intervention," Sexual Transmitted Diseases, Vol. 35, No. 6, 2008, pp. 624-630. http://dx.doi.org/10.1097/OLQ.0b013e31816b3208

[33] J. T. F. Lau, J. Gu, L. Zhang, F. Cheng, Y. Zhang, J. Zhang, et al., "Comparing Prevalence of HIV-Related Be- 
haviors among Female Injecting Drug Users (IDU) Whose Regular Sexual Partner Was or Was Not IDU in Sichuan and Yunnan Provinces, China," AIDS Care, Vol. 21, No. 7, 2009, pp. 909-917.

http://dx.doi.org/10.1080/09540120802612790

[34] I. Abdullah, "Sangkan Paran Gender," Pustaka Pelajar, Yogyakarta, 1997.

[35] Koentjaraningrat, "Javanese Culture," Oxford University Press, Singapore City, 1985.

[36] N. J. Ford, Z. Shaluhiyah and A. Suryoputro, "A Rather
Benign Sexual Culture: Socio-Sexual Lifestyles of Youth in Urban Central Java, Indonesia," Population Space and Place, Vol. 13, No. 1, 2007, pp. 59-76. http://dx.doi.org/10.1002/psp.443

[37] M. Burke, M. Rajabu and J. Burke, "Maximizing Male Participation in Prevention of Mother to Child Transmission Programs in Tanzania," Proceedings of Tenth XVII International AIDS Conference, Bangkok, 2004. 